\title{
Measurement of Functional Residual Capacity by Sulfur Hexafluoride in Small-Volume Lungs during Spontaneous Breathing and Mechanical Ventilation ${ }^{1}$
}

\author{
ANDREAS SCHULZE, PETER SCHALLER, ANDREAS TÖPFER, AND HARESH KIRPALANI \\ McMaster University, Neonatology Division, Hamilton, Ontario, L8N 3Z5, Canada [A.S., H.K.] and University \\ of Dresden, Faculty of Medicine, Children's Hospital, Division of Neonatology, Dresden, Germany [P.S., A.T.]
}

\begin{abstract}
We modified a sulfur hexafluoride $\left(\mathrm{SF}_{6}\right)$ washout technique to allow functional residual capacity (FRC) determinations in small-volume lungs both during spontaneous breathing and controlled mechanical ventilation. This method facilitates measurements in subjects who attempt spontaneous breaths between ventilator-generated breaths. We wished to confirm the accuracy and precision of the measurements and the method's sensitivity to change. The method uses a pneumotach together with a fast, mainstream infrared $\mathrm{SF}_{6}$ sensor mounted between the endotracheal tube and the ventilator circuit. A low flow of pure $\mathrm{SF}_{6}$ is delivered into the constant gas flow of the ventilator circuit to wash in tracer gas at a concentration of less than $2 \%$. The flow signal and the instantaneous $\mathrm{SF}_{6}$ concentration is processed on-line by a computer. The calibration of the $\mathrm{SF}_{6}$ sensor's nonlinear signal and the ability of the flow sensor to reflect flow values precisely near zero flow had a major impact on the accuracy of the FRC estimate. This accuracy was tested by comparing measured FRC values with a dummy lung's true FRC that was varied from 7 to $70 \mathrm{~mL}$. The comparison differed by $0.7 \pm 3.2 \%$ (mean $\pm \mathrm{SD}$; range, -5.1 to $7.8 \%$ ). As a measure of reproducibility (precision) across 20 FRC determinations in five adult rabbits, the average coefficient of variation was $1.7 \%$ (range, 0.57 to $4.33 \%$ ) during continuous positive airway pressure and $1.98 \%$ (range, 0.35 to $3.81 \%$ ) during controlled mechanical ventilation. The method proved sensitive to changes in FRC related to changes in airway pressure. We conclude that $\mathrm{SF}_{6}$ washout allowed unbiased and precise FRC measurements under the circumstances of this study in the range of 5 to 100 mL of FRC. (Pediatr Res 35: 494-499, 1994)
\end{abstract}

\section{Abbreviations}

CMV, controlled mechanical ventilation

CPAP, continuous positive airway pressure

FRC, functional residual capacity

$P_{\text {aon }}$ pressure at the airway opening

PEEP, positive end-expiratory pressure

$\mathrm{SF}_{6}$, sulfur hexafluoride

Received July 15, 1993; accepted November 24, 1993.

Correspondence: Andreas Schulze, M.D., McMaster University, HSC, Dept. Pediatrics, Room 4G40, 1200 Main Street West, Hamilton, Ontario L8N 3Z5, Canada.

Supported by a grant from the Regional Medical Associates of Hamilton, Ontario, Canada.

' Presented in part at the Fourth Annual Pediatric Research Meeting. May 1992. University of Manitoba, Winnipeg, Canada, and the Midatlantic Conference on Perinatal Research, October 1992, Irvington, VA.
The FRC is a major determinant of the efficacy of pulmonary gas exchange. Widely used therapeutic interventions such as CPAP during spontaneous breathing and PEEP during CMV aim to maintain FRC in a variety of lung diseases. However, easily applicable technology for FRC measurements that does not interfere with nursing care has not to date been available for routine management in neonatal intensive care. $\mathrm{SF}_{6}$ washout (15 ) is a potentially suitable technique for neonates receiving intensive care, including those who need near $100 \% \mathrm{O}_{2}(6)$.

The goal of our study was to assess an FRC measurement technique for small-volume lungs that can be used both in spontaneously breathing subjects and during CMV in terms of a near gold standard comparison with a lung model lung volume and in vivo demonstration of reproducibility. Furthermore, the specific objective was to demonstrate a validity by testing whether the technique can accurately reflect changes in FRC induced by therapeutic interventions such as the elevation of CPAP or an increase in PEEP during CMV.

\section{MATERIALS AND METHODS}

Ventilator system. The FRC equipment was set up in conjunction with a previously described ventilator for infants (7-9) that can provide the conventional modes of CPAP and CMV. Briefly, the ventilator uses a flow sensor and a pressure sensor directly at the endotracheal tube connector. The pneumotach (10) has a dead space of $0.9 \mathrm{~mL}$ and a resistance of $1.1 \mathrm{kPa} \cdot \mathrm{s} / \mathrm{L}$ at $5 \mathrm{~L} /$ min. Feedback loops control the $P_{a o}$ and/or the flow at the endotracheal tube. The ventilator's pneumatic unit is fed with a continuous constant flow of a humidified air-oxygen mixture. The flow and $P_{a o}$ signals are continuously available and can be used for analysis of pulmonary mechanics.

The feedback loops enable specific flow rates to be set at the endotracheal tube. Therefore, it is possible to calculate the "insufflation compliance" (11) during CMV. During the CPAP mode, an "occlusion compliance" (12) was measured by setting the flow to zero at end-inspiration.

FRC measurement technique. The $\mathrm{SF}_{6}$ analyzer used was a prototype for fast, mainstream, infrared analysis developed by Siemens (Siemens-Elema, Solna, Sweden). The internal dead space of the cuvette was minimal at $1 \mathrm{~mL}$. Small mesh screens were inserted on both ports of the measurement chamber to facilitate tracer gas mixing with air. The resistance of the cuvette with the mesh screens was $0.26 \mathrm{kPa} \cdot \mathrm{s} / \mathrm{L}$ at $5 \mathrm{~L} / \mathrm{min}$. To get different concentrations of $\mathrm{SF}_{6}$ in air for sensor calibration, we mixed a low flow of pure $(99.99 \%) \mathrm{SF}_{6}$ with a series of known flows of air. A low, constant $\mathrm{SF}_{6}$ flow was obtained from a highpressure $\mathrm{SF}_{6}$ cylinder with an adjustable regulator (Matheson Gas Products, Montgomeryville, PA) and measured by water displacement. The flowmeter used to measure the different air 
flows was calibrated with a gas meter that guarantees a measurement error of less than $\pm 0.5 \%$ over a flow range of $10-1000$ $\mathrm{L} / \mathrm{h}$ (Junkalor Inc., Dessau, Germany). The calibration curve of the $\mathrm{SF}_{6}$ sensor is nonlinear because the intensity of the original light beam decreases exponentially to the concentration of the light-absorbing gas according to the Beer-Lambert law if the path length (size of the cuvette) is constant (13). The computer internally linearizes the calibration curve, and all subsequent calculations are based on a linear characteristic. The cuvette was mounted between the endotracheal tube and the flow sensor of the ventilator. During wash-in a low flow of pure $\mathrm{SF}_{6}$ was delivered by a side port into the constant flow of $9 \mathrm{~L} / \mathrm{min}$ of humidified gas entering the pneumatic unit of the ventilator (Fig. 1).

The $\mathrm{SF}_{6}$ monitor, the valve to start and to stop $\mathrm{SF}_{6}$ delivery, and the ventilator's flow and pressure outlet ports were interfaced with a computer. Signal processing, all calculations, and on-off commands were performed by our own algorithms with the Workbench PC software package (Strawberry Tree Inc., Sunnyvale, $C A$ ). Because the response time of the $\mathrm{SF}_{6}$ sensor is slow $(10-15 \mathrm{~ms})$ relative to the flow sensor, the computer program has a 10-ms lag time built in for the flow to synchronize the two signals better. Wash-in was started by clicking on a switch icon on the computer screen. The final on-switch output via the digital-analog converter directly to the $\mathrm{SF}_{6}$ valve was postponed by the computer to the start of the next expiration (crossing the zero flow line from positive to negative). Thus, the tracer gas primed the pneumatic unit of the ventilator during that expiration and was delivered at a constant concentration to the subject during the next inspirations. Inspired and expired $\mathrm{SF}_{6}$ concentration was displayed over time on the computer screen (Fig. 2). Once equilibrium was achieved the off-switch mechanism was activated by disabling the switch icon. The computer turned the $\mathrm{SF}_{6}$ delivery valve off at end-inspiration so that the pneumatic

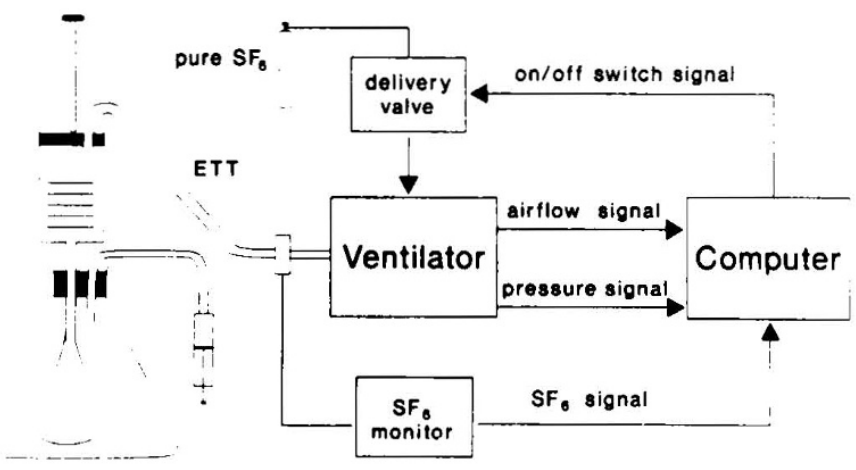

Fig. 1. FRC measuring system attached to a lung model. The adjustable volume inside the syringe represents the FRC. The bag is exposed to a supraatmospheric pressure inside the bottle to ensure complete endexpiratory emptying so that only the volume inside the syringe remains as FRC. The other (small) syringe is used to pressurize the bottle. The ventilator measures both the airflow and the pressure at the endotracheal tube $(E T T)$ level.

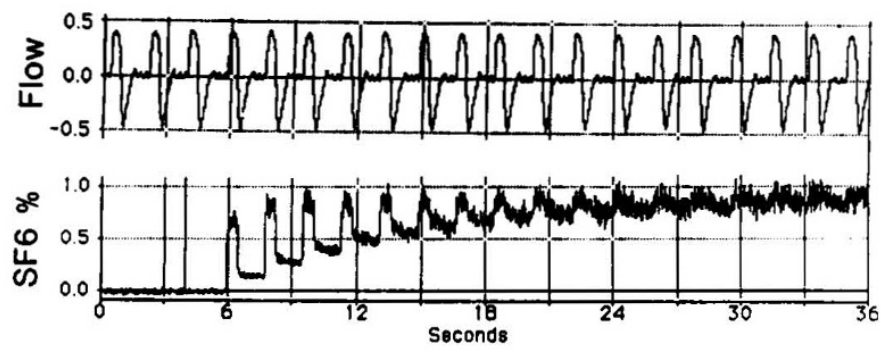

Fig. 2. Airflow of spontaneous breathing and $\mathrm{SF}_{6}$ concentration at the endotracheal tube level during a wash-in period lasting for around 30 s. Units: 1.0 corresponds to $5 \mathrm{~L} / \mathrm{min}$ or $1 \% \mathrm{SF}_{6}$, respectively. unit of the ventilator was flushed with air free of tracer gas during the next expiration and delivered pure air for the first washout inspiration.

With starting washout (Fig. 3), the computer continuously calculated the $\mathrm{SF}_{6}$ flow as the product of air flow and $\mathrm{SF}_{6}$ concentration for each sampled pair of measured values. The sampling rate was $100 \mathrm{~Hz}$. The total volume of expired $\mathrm{SF}_{6}$ was then given as the integral of the $\mathrm{SF}_{6}$ flow over time. During the initial inspiration, rebreathing of $\mathrm{SF}_{6}$ from the pneumotach and its short connectors to the ventilator circuit and to the $\mathrm{SF}_{6}$ cuvette was inevitable. This volume was calculated in the same way and always subtracted from the total amount of exhaled tracer gas. The exhaled $\mathrm{SF}_{6}$ volume was displayed on the screen over time. The measurement of the washout curve was stopped when no further increase in the calculated volume occurred. To obtain FRC, we divided this volume by the end-expiratory $\mathrm{SF}_{6}$ concentration of the last expiration before starting washout. The program displayed the calculated FRC in a window on the screen.

Mechanical lung model-near gold standard measure. The model consisted of a thin-walled balloon attached on top of a syringe (Fig. 1). It was ventilated through an endotracheal tube inserted through the syringe's plunger. The balloon was slightly pressurized from outside to guarantee its complete end-expiratory emptying so that only the known volume inside the syringe remained as "FRC." To determine the accuracy and precision of the $\mathrm{SF}_{6}$ washout technique, we conducted FRC measurements while the test lung was ventilated with tidal volumes of 6,10 , and $20 \mathrm{~mL}$. Its FRC was varied between 7 and $70 \mathrm{~mL}$. Ventilator frequencies above 70 beats per min were not tested.

Animal model. This study was approved by the McMaster University, Hamilton, Animal Research Ethics Board (no. 9110-234).

Five adult New Zealand White rabbits (mean body weight, $2530 \mathrm{~g}$; range, $2450-2600 \mathrm{~g}$ ) were anesthetized with $100 \mathrm{mg}$ of ketamine hydrochloride and $5 \mathrm{mg}$ of xylazine. Anesthesia was maintained by supplemental boluses of pentobarbital. We attempted to keep the anesthetic level at surgical anesthesia, and not more, to minimize depression of spontaneous breathing efforts. Infusion fluids were given at $3 \mathrm{~mL} / \mathrm{kg} / \mathrm{h}$ i.v. Tracheos-
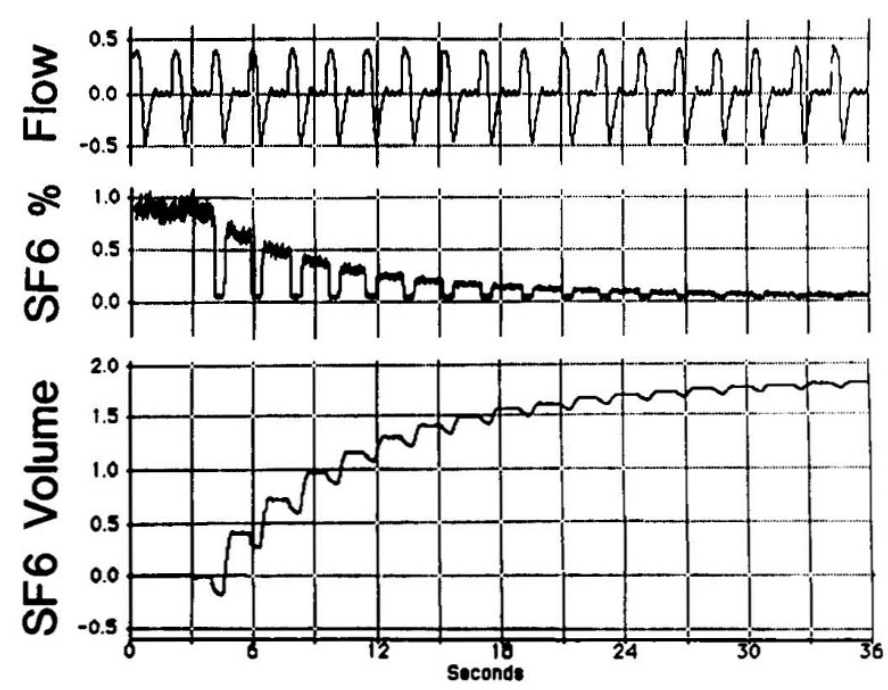

Fig. 3. $\mathrm{SF}_{6}$ washout. The total amount of exhaled $\mathrm{SF}_{6}$ volume (lower panel, 1.0 unit corresponds to $0.1 \mathrm{~mL}$ ) is calculated as

$$
\int F_{\mathrm{SF} 6} \cdot V^{\prime} d t \text {. }
$$

with $\mathrm{F}_{\mathrm{SF} 6}$ being the instantaneous fractional concentration of the tracer gas and $V^{\prime}$ being the flow of spontaneous breathing. Note that during early inspiration with each breath a small amount of $\mathrm{SF}_{6}$ is washed in as a result of rebreathing $\mathrm{SF}_{6}$-enriched dead space volume. Therefore, the signal of the net exhaled $\mathrm{SF}_{6}$ volume always drops initially during inspiration. 
tomy was performed on each animal, and the trachea was cannulated with a $2.5-\mathrm{mm}$ inner diameter endotracheal tube (length, $150 \mathrm{~mm}$ ) secured in place by a peritracheal ligature. This endotracheal tube size was chosen because it is commonly used in neonatal intensive care. The animal was then connected to the ventilator in the supine position and had ventilation during the rest of the surgical procedure with CMV using a PEEP of 0.2 $\mathrm{kPa}$. An arterial line was inserted through the left carotid artery for intermittent determination of arterial blood gases.

Study protocol. Each animal was exposed to four different levels of CPAP in the following order: $0.2,0,0.4$, and $0.6 \mathrm{kPa}$. At least $5 \mathrm{~min}$ were allowed for stabilization at each level before measurements were conducted. The FRC was measured in triplicate at each CPAP level. The occlusion compliance was measured at CPAP of $0.2 \mathrm{kPa}$ before the FRC determinations were started.

Afterward, CMV was started. For this part of the study, full neuromuscular paralysis was initiated and maintained with i.v. pancuronium bromide $(0.2 \mathrm{mg} / \mathrm{kg} / \mathrm{h})$. Tidal volume and ventilator rate were adjusted to maintain normocapnia.

$A$ very slow inflation of the lung was then performed from zero $P_{\mathrm{ao}}$ up to $0.7 \mathrm{kPa}$ with a constant flow of $5 \mathrm{~mL} / \mathrm{s}$. This quasi-static pressure-volume characteristic of the lung was also recorded with the Workbench PC software.

Subsequently, the PEEP was elevated from 0 to $0.6 \mathrm{kPa}$ in steps of $0.2 \mathrm{kPa}$. Triple FRC measurements were performed after $15 \mathrm{~min}$ of CMV at each level. Finally, the quasi-static inflation of the lung was repeated.

Statistics. Values are presented as mean \pm SD. Linear regression was performed with the method of least squares to obtain the line of best fit. Two-way analysis of variance was used to check for differences in mean accuracy (i.e. difference between measured and true value of the model's FRC) being related to tidal volume or to the level of true FRC (Fig. 4).

Because each FRC “determination" in the animal experiments represents triplicate measurements over a period of about $5 \mathrm{~min}$, the FRC reproducibility (precision) could be assessed by the coefficient of variation in percent (SD. 100/average of the three measurements of FRC) (Table 1).

\section{RESULTS}

Accuracy of $\mathrm{SF}_{6}$ washout technique as tested on mechanical lung model. The measured FRC was significantly correlated with the true FRC ( $r=0.99 ; p<0.0001$; Fig. 4). The regression line was defined by the following function: $\mathrm{FRC}_{\mathrm{SF} 6}=0.986 \cdot \mathrm{FRC}_{\text {true }}$ +0.306 , which is not significantly different from the line of

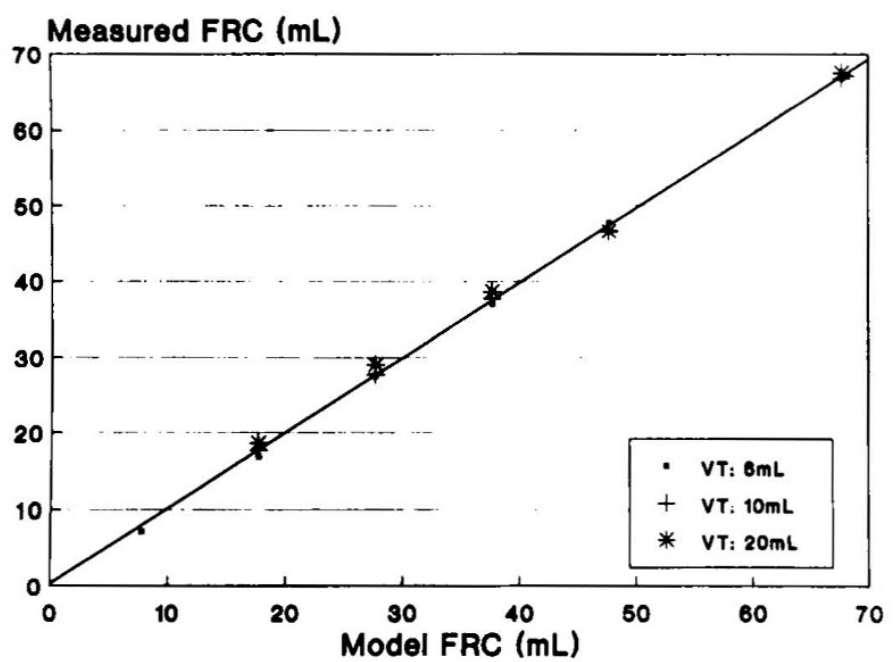

Fig. 4. FRC as estimated with the $\mathrm{SF}_{6}$ washout technique vs the "true" test lung FRC. The regression line is shown. It is not significantly different from the line of identity. $V T$, tidal volume. identity. The difference between the paired measured and true FRC values was $0.70 \pm 3.2 \%$ (range, -5.1 to $7.8 \%$ ). Statistically, there was no evidence of differences in mean accuracy being related to tidal volume or to the level of true FRC. In other words, the method was uniformly accurate at all tested tidal volumes and over the range of the tested true FRC levels.

Physiologic variability of $F R C_{S F}$ during $C P A P$ and $C M V$. Each of the $40 \mathrm{FRC}_{\mathrm{SF} 6}$ determinations during CPAP and during CMV is the average of three individual successively repeated measurements. The coefficient of variation (i.e. the reproducibility or "precision" of these measurements) did not show any trend with the different levels of CPAP or end-expiratory pressure, nor did it show any systematic differences between animals. The average coefficient of variation across the 20 measurements during CPAP was $1.70 \%$ (range, 0.57 to $4.33 \%$ ). It was $1.98 \%$ (range, 0.35 to $3.81 \%$ ) across the 20 measurements during CMV (Table 1).

Effect of the end-expiratory $P_{a o}$ on the FRC. The measured changes in FRC in response to stepwise variations in the endexpiratory $\mathrm{P}_{\mathrm{a}}$ by $0.2 \mathrm{kPa}$ were clearly far beyond the variability range of the method itself both during CPAP and CMV (Table 1).

The changes in lung volume as measured with the $\mathrm{FRC}_{\mathrm{SF} 6}$ technique during CMV precisely followed the quasi-static pressure-volume characteristic in the animals 1,2 , and 4 . The rise in $\mathrm{FRC}_{\mathrm{SF} 6}$ per unit of pressure was steeper than the pressure-volume curve in animal 5 and especially in animal 3 (Fig. 5). This latter animal was the only one showing a marked deterioration of its lung compliance and decrease of the FRC after paralysis right between the two series of FRC measurements (Table 1).

\section{DISCUSSION}

We have modified a previously described $\mathrm{SF}_{6}$ washout technique $(1,2,5,6)$ to allow FRC measurements in subjects with small-volume lungs and preserved spontaneous breathing activity on a variety of mechanical ventilators. Our specific aim was to develop a technique that interferes less than hitherto described apparatuses $(6,14)$ with the routine therapeutic situation in neonatal intensive care. This study tests the accuracy, precision, and responsiveness to therapeutic modalities of this modified technique under experimental conditions.

$S F_{6}$ sensor and flow sensor. The technique depends on instantaneous and simultaneous measurement of the $\mathrm{SF}_{6}$ concentration and flow at the airway opening. The response time of the infrared $\mathrm{SF}_{6}$ analyzer is below $20 \mathrm{~ms}$ (3). It also has been shown previously that the sensor is not significantly disturbed by carbon dioxide or variations in oxygen concentration $(3,4)$. We did not recheck the sensor with respect to these characteristics, but we obtained the calibration curve up to $2 \% \mathrm{SF}_{6}$ before the bench tests shown in Figure 4. The accuracy of the FRC measurements was highly sensitive to the quality of the calibration curve, as shown with our preliminary measurements on the mechanical model. However, for the purpose of our FRC calculation, we did not need to guarantee correct absolute $\mathrm{SF}_{6}$ concentration values. We will calculate accurate FRC values as long as the slope of the $\mathrm{SF}_{6}$ calibration curve is picked up correctly by the calibration procedure. Only if the slope is inaccurate will we get biased results. This result occurs because the measured volume of washed out $\mathrm{SF}_{6}$ is divided by the measured end-expiratory $\mathrm{SF}_{6}$ concentration to obtain FRC and because we are measuring these two values with the same transducer.

The sensor has a fast response achieved at the expense of a high signal-to-noise ratio (3). Although the noise appears large (Figs. 2 and 3), the computer obviously could estimate the mean $\mathrm{SF}_{6}$ concentration precisely, as shown in Figure 4. However, the quality of the signal did not allow a precise FRC calculation on the basis of wash-in curves (Fig. 2), and all calculations were based on washout curves. The zero-flow calibration of the flow monitor is a critical prerequisite for this method to obtain an 
Table 1. FRC and respiratory system compliance as measured during CPAP and mechanical ventilation with PEEP in five rabbits*

\begin{tabular}{|c|c|c|c|c|c|c|c|c|c|c|}
\hline \multirow{3}{*}{$\begin{array}{c}\text { Animal } \\
\text { no. }\end{array}$} & \multirow{3}{*}{$\begin{array}{c}\text { Coccl } \\
(\mathrm{mL} / \mathrm{kPa})\end{array}$} & \multicolumn{8}{|c|}{ FRC (mL) (mean, CV\%) } & \multirow{3}{*}{$\begin{array}{c}\text { Cinsu } \\
(\mathrm{mL} / \mathrm{kPa})\end{array}$} \\
\hline & & \multicolumn{4}{|c|}{$\mathrm{CPAP}(\mathrm{kPa})$} & \multicolumn{4}{|c|}{$\operatorname{PEEP}(\mathrm{kPa})$} & \\
\hline & & 0 & 0.2 & 0.4 & 0.6 & 0 & 0.2 & 0.4 & 0.6 & \\
\hline 1 & 24 & $\begin{array}{c}19.1 \\
1.20\end{array}$ & $\begin{array}{c}21.9 \\
1.37\end{array}$ & $\begin{array}{c}29.9 \\
0.57\end{array}$ & $\begin{array}{c}34.5 \\
1.30\end{array}$ & $\begin{array}{c}20.5 \\
1.30\end{array}$ & $\begin{array}{c}23.5 \\
1.49\end{array}$ & $\begin{array}{c}28.9 \\
0.35\end{array}$ & $\begin{array}{c}33.9 \\
2.60\end{array}$ & 23 \\
\hline 2 & ND & $\begin{array}{c}22.6 \\
1.11\end{array}$ & $\begin{array}{c}28.3 \\
1.80\end{array}$ & $\begin{array}{l}32.1 \\
1.65\end{array}$ & $\begin{array}{c}39.2 \\
0.81\end{array}$ & $\begin{array}{c}19.5 \\
3.12\end{array}$ & $\begin{array}{c}24.8 \\
1.73\end{array}$ & $\begin{array}{c}29.8 \\
1.00\end{array}$ & $\begin{array}{c}36.8 \\
3.29\end{array}$ & 26 \\
\hline 3 & 20 & $\begin{array}{c}17.9 \\
1.13\end{array}$ & $\begin{array}{c}22.3 \\
2.48\end{array}$ & $\begin{array}{c}25.6 \\
1.78\end{array}$ & $\begin{array}{l}38 \\
2.74\end{array}$ & $\begin{array}{l}7.7 \\
1.30\end{array}$ & $\begin{array}{c}10.5 \\
0.95\end{array}$ & $\begin{array}{c}15.5 \\
3.29\end{array}$ & $\begin{array}{l}23.7 \\
2.25\end{array}$ & 8 \\
\hline 4 & 36 & $\begin{array}{l}23.6 \\
4.33\end{array}$ & $\begin{array}{c}29.1 \\
1.39\end{array}$ & $\begin{array}{c}38.5 \\
3.91\end{array}$ & $\begin{array}{c}48.4 \\
1.96\end{array}$ & $\begin{array}{c}25.4 \\
3.81\end{array}$ & $\begin{array}{r}30.10 \\
0.69\end{array}$ & $\begin{array}{c}38.4 \\
1.73\end{array}$ & $\begin{array}{c}45.0 \\
2.08\end{array}$ & 36 \\
\hline 5 & 19 & $\begin{array}{c}18.6 \\
1.13\end{array}$ & $\begin{array}{c}23.2 \\
1.56\end{array}$ & $\begin{array}{c}33.4 \\
1.07\end{array}$ & $\begin{array}{c}35.9 \\
0.74\end{array}$ & $\begin{array}{c}18.9 \\
1.56\end{array}$ & $\begin{array}{c}22.8 \\
1.56\end{array}$ & $\begin{array}{c}27.8 \\
2.77\end{array}$ & $\begin{array}{c}32.9 \\
2.77\end{array}$ & 22 \\
\hline
\end{tabular}

* FRC data represent mean (top value) and coefficient of variation ( $\mathrm{CV}$, in \%; bottom value) of three consecutive measurements. Coccl, compliance of the respiratory system as measured during spontaneous breathing at $0.2 \mathrm{kPa}$ of CPAP by an occlusion technique (12); Cinsu, compliance of the respiratory system as measured during mechanical ventilation by a constant-flow inflation method (11); ND, not done.

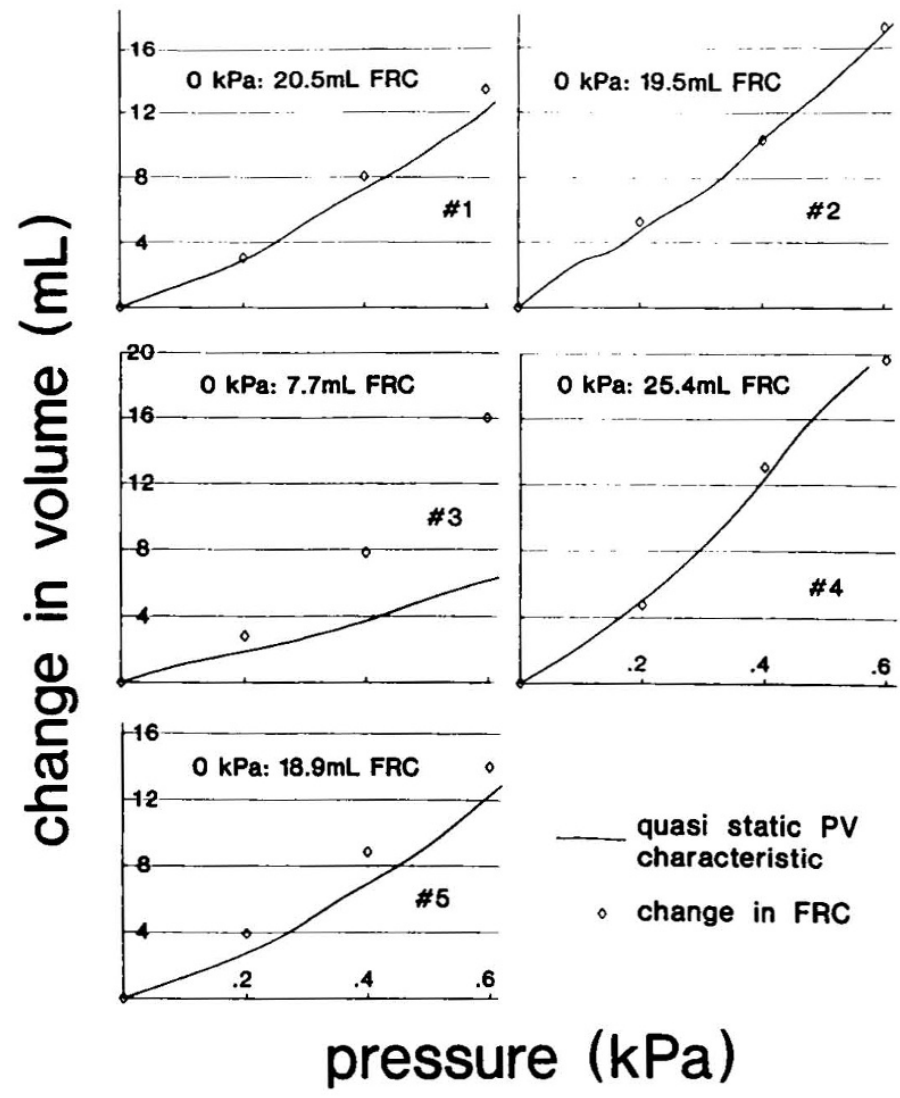

Fig. 5. Changes in lung volume with increasing airway pressure according to FRC measurements with $\mathrm{SF}_{6}$ and according to the quasi-static pressure-volume curve.

unbiased FRC estimate. Whenever the flow monitor's signal deviates slightly from zero during periods of zero flow, a systematic error will occur in the FRC estimate. We always calibrated the flow sensor carefully before the experiments. We did not test other types of flow sensors for this technique, and no problems occurred with moisture inside the heated pneumotach in our animal experiments. However, the resistive pressure drop across the pneumotach may change substantially if any particles such as secretions, water droplets, or surfactant foam get into the sensor. This potential problem is specific to those methods that rely on the precision of flow measurements inside the airway. We inserted small metal mesh screens on either side of the interconnected sensors. These screens serve two purposes: they withhold any contaminating particles, and they guarantee perfect mixing of the tracer gas.

Speed of $S F_{6}$ washout. $\mathrm{SF}_{6}$ was washed out remarkably fast in our rabbits, so it usually took no more than $2 \mathrm{~min}$ to perform one FRC measurement (Figs. 2 and 3). This finding may appear surprising in view of the high molecular weight of 146 in comparison with other gases used for FRC measurements like helium (molecular weight $=4$ ). The diffusivity (D) of a gas is proportional to the square root of its molecular mass, and washout of alveolar gas is assumed to occur by diffusion in addition to convection from the alveolar compartment up to approximately the 17th bronchial generation. The time course of this process depends on the peripheral volume (V) of the gas and the distance (d) and cross-sectional area (CA) through which it diffuses. Thus, the initial alveolar fractional concentration $\left(\mathrm{F}_{0}\right)$ decreases over time according to

$$
F_{t}=F_{0} \cdot e^{-\frac{t}{\tau}}
$$

where $\tau$ is proportional to

$$
\frac{d \cdot V}{D \cdot C A}
$$

Although this is a simplification (1) (for instance, the assumption that the test gas concentration remains zero in the proximal airways is violated in our setup by rebreathing, as Figure 3 clearly shows), it demonstrates that under these ideal conditions $\mathrm{SF}_{6}$ should be washed out approximately 6 times slower than helium (square root of 146/4). The fact that washout was so fast in our experiments suggests that mechanisms other than diffusion may play a major role in mixing $\mathrm{SF}_{6}$. Cardiac churning and convection facilitated by the high respiratory rates might be contributing factors. However, it may also be implied from the above considerations that whenever $\mathrm{SF}_{6}$ has to move over a longer distance or smaller cross-sectional area by diffusion only, the washout might be significantly prolonged. Therefore, our results about the feasibility, accuracy, and precision of the $\mathrm{SF}_{6}$ technique may not necessarily hold true for specific disease states like bronchopulmonary dysplasia. Although no significant difference was seen in normal adults between helium and $\mathrm{SF}_{6}$ FRC measurements (5), nitrogen and $\mathrm{SF}_{6}(2)$, and body plethysmography and $\mathrm{SF}_{6}(2$, 5), the $\mathrm{SF}_{6}$ technique gave systematically lower estimates in comparison with helium in adult patients with chronic obstructive lung disease (5).

Other properties of $S F_{6} . \mathrm{SF}_{6}$ is a nontoxic, inert, odorless gas. The Bunsen solubility coefficients of $\mathrm{SF}_{6}$ in lung tissue and blood are even smaller ( 0.0068 and 0.00084 , respectively) than those 
of helium $(15,16)$. Therefore, dissolved $\mathrm{SF}_{6}$ cannot be a significant source of error during FRC measurements.

Comparison with other techniques for FRC measurement in small-volume lungs. The $\mathrm{SF}_{6}$ method previously described for small neonates $(6,14)$ used the same infrared $\mathrm{SF}_{6}$ monitor as we did. However, these authors modified a specific type of ventilator (Servo 900C, Siemens-Elema, Sweden) for the purpose of their FRC measurements. In this system, the analyzer is unable to be used in its described form with other ventilators. Additional components of their system include electromagnetic inspiratory and expiratory auxiliary valves, two heated pneumotachs (Fleisch no. 00, Lausanne, Switzerland), and an $\mathrm{SF}_{6}$ dispensing unit. Although the additional dead space load to the patient during the measurement procedure is small $(0.6$ to $0.8 \mathrm{~mL})$, the additional expiratory resistive load was not described. The accuracy and precision of their technique according to test results with a physical lung model of known FRC ranging from 5 to $60 \mathrm{~mL}$ appears to be identical with our results reported here. However, measurements cannot be obtained in the presence of intermittent spontaneous breaths or during CPAP. Furthermore, when the technique was used in a clinical setting, the infants were disconnected from their ventilator, switched to the modified ventilator with the measuring system, and sedated or paralyzed to abolish spontaneous respiratory efforts during measurements (6).

Our technique requires the insertion of the flow sensor and the $\mathrm{SF}_{6}$ sensor between the endotracheal tube and the ventilator circuit. No other manipulations are necessary near the patient. The technique can be used with all constant-flow infant ventilators. The fact that our method works both during spontaneous breathing and with ventilator-generated breaths of varying tidal volumes is a particular advantage because infants usually do initiate spontaneous breaths between ventilator-generated cycles.

The advantage of all $\mathrm{SF}_{6}$ techniques in comparison with other gas dilution techniques $(17,18)$ is that a high concentration of inspired oxygen does not preclude measurements or impair the precision. For measurements with the open circuit nitrogen washout technique $(18,19)$, the infant also has to be connected to a second ventilator. The bag-in-bottle rebreathing systems either have to use $\mathrm{CO}_{2}$ absorbers in the circuit (20) or can only allow for a short period of equilibration, which might be too short for diseased lungs $(21,22)$. Recently described modified plethysmographic techniques also still appear cumbersome because the patient has to be moved into a box sealed around the face (23-26).

$F R C$ during regular $C P A P$ and $C M V$. During this study, the animals did not display much physiologic variability of the FRC within the time of three consecutive measurements. The reproducibility of our measurements was excellent in comparison with other reports studying FRC in the range below $100 \mathrm{~mL}$ (17). It is interesting that the FRC changes in response to an increased PEEP almost exactly followed the quasi-static pressure-volume curve in all our animals with normal lungs. However, the pressure-volume curve did not predict the FRC changes in one experiment. This particular experiment was conducted in the only rabbit that had a markedly impaired lung function during the second study period under CMV as indicated by its decreased lung compliance and low FRC. The higher-than-predicted rise in FRC with increasing PEEP in this situation might be explained by reopening of previously noncommunicating air spaces to the airway system. The quasi-static pressure-volume curve may not reflect reopening. On the other hand, the $\mathrm{SF}_{6}$ technique as a gas dilution method will include "trapped air spaces" in the FRC estimate as soon as they are reopened.

We did not examine in this study to what extent the presence of leaks around the endotracheal tube may invalidate FRC measurements with our $\mathrm{SF}_{6}$ setup. Gas leaks are a potential source of error for all known methods of assessing FRC in infants. Some authors have tried to reduce this problem by exerting a gentle external pressure below the larynx to seal the endotracheal tube around the trachea during measurements $(6,21,22)$. Other investigators attempted a mathematical correction for the endotracheal tube leak (27). However, leaks may affect the various methods of FRC measurement differently. For instance, we do not sample during the end-inspiration period of the ventilator when leak flows usually peak. In contrast, the peak leak flow most likely has a major impact on some of the helium dilution techniques (27).

In conclusion, the method described is adaptable to most ventilators with which we are familiar that are for infants. In light of the accuracy with a near gold standard, the high reproducibility of the data, and its responsiveness to a common lung volume recruiting maneuver, this method may have a clinical monitoring application.

Acknowledgments. The authors thank Robin S. Roberts, Professor of Biostatistics at McMaster University Medical School, Hamilton, Ontario, Canada, for his help with the statistics. We thank Siemens-Elema, Solna, Sweden, for their generosity in making available to us the sulfur hexafluoride sensor.

\section{REFERENCES}

1. von Nieding G, Loellgen H, Smidt U, Linde H 1977 Simultaneous washout of helium and sulfur hexafluoride in healthy subjects and patients with chronic bronchitis, bronchial asthma, and emphysema. Am Rev Respir Dis 116:649660

2. Jonmarker C, Jansson L, Jonson B, Larsson A, Werner O 1985 Measurement of functional residual capacity by sulfur hexafluoride washout. Anesthesiology 63:89-95

3. Jonmarker C, Castor R, Drefeldt B, Werner O 1985 An analyzer for in-line measurement of expiratory sulfur hexafluroide concentration. Anesthesiology 63:84-88

4. East TD, Andriano KP, Pace NL 1987 Automated measurement of functional residual capacity by sulfur hexafluoride washout. J Clin Monit 3:14-21

5. East TD, Wortelboer PJ, van Ark E, Bloem FH, Peng L, Pace NL, Crapo RO, Drews D, Clemmer TP 1990 Automated sulfur hexafluoride washout functional residual capacity measurement system for any mode of mechanical ventilation as well as spontaneous respiration. Crit Care Med 18:84-91

6. Vilstrup CT, Björklund LJ, Larsson A, Lachmann B, Werner O 1992 Functional residual capacity and ventilation homogeneity in mechanically ventilated small neonates. J Appl Physiol 73:276-283

7. Schaller P, Schulze A 1991 A ventilator generating a positive or negative internal compliance. Ups J Med Sci 96:219-234

8. Schulze A, Schaller P, Gehrhardt B, Mädler HJ, Gmyrek D 1990 An infant ventilator technique for resistive unloading during spontaneous breathing. Results in a rabbit model of airway obstruction. Pediatr Res 28:79-82

9. Schulze A, Schaller P, Töpfer A, Kirpalani H 1993 Resistive and elastic unloading to assist spontaneous breathing does not change functional residual capacity. Pediatr Pulmonol 16:170-176

10. Schaller P, Mädler HJ, Schulze A, Böhme B, Leupold W 1985 Ein LamellenSpirorezeptor für die Pneumotachographie bei Frühgeborenen und Säuglingen. Z Klin Med 40:947-949

11. Schulze A, Schaller P, Dinger J, Winkler U, Gmyrek D 1990 A method of calculating total respiratory system compliance from resonant frequency: validity in a rabbit model. Pediatr Res 28:599-602

12. Olinsky A, Bryan AC, Bryan MH 1976 A simple method of measuring total respiratory system compliance in newborn infants. S Afr Med J 50:128-130

13. Limbaugh CC 1985 The infrared emission-absorption method for temperature and species partial pressure determination in flames and plumes. In: Wormhoudt J (ed) Infrared Methods for Gaseous Measurements. Marcel Dekker Inc., New York, pp 197-245

14. Vilstrup C, Gommers D, Bos JA, Lachmann B, Werner O, Larsson A 1992 Natural surfactant instilled in premature lambs increases lung volume and improves ventilation homogeneity within five minutes. Pediatr Res 32:595599

15. Cander L 1959 Solubility of inert gases in human lung tissue. J Appl Physiol $14: 538-540$

16. Hlastala MP, Meyer M, Riepl G, Scheid P 1980 Solubility of helium, argon, and sulfur hexafluoride in human blood measured by mass spectrometry. Undersea Biomed Res 7:297-304

17. Gerhardt T, Reifenberg L, Hehre D, Feller R, Bancalari E 1986 Functional residual capacity in normal neonates and children up to 5 years of age determined by a $\mathrm{N}_{2}$ washout method. Pediatr Res 20:668-671

18. Sivan Y, Deakers TW, Newth JL 1990 An automated bedside method for measuring functional residual capacity by $\mathrm{N}_{2}$ washout in mechanically ventilated children. Pediatr Res 28:446-450

19. Sivan Y, Deakers TW, Newth CJ 1990 Functional residual capacity in ventilated infants and children. Pediatr Res 28:451-454

20. Yuksel B, Greenough A, Chan V, Ross Russell R 1993 Comparison of helium dilution and nitrogen washout measurements of functional residual capacity in premature infants. Pediatr Pulmonol 16:197-200

21. Bose C, Wood B, Bose G, Donlon D, Friedman M 1990 Pulmonary function 
following positive pressure ventilation initiated immediately after birth in infants with respiratory distress syndrome. Pediatr Pulmonol 9:244-250

22. Bose CL, Lawson EE, Greene A, Mentz W, Friedman M 1986 Measurement of cardiopulmonary function in ventilated neonates with respiratory distress syndrome using rebreathing methodology. Pediatr Res 20:316-320

23. Edberg KE, Sandberg K, Silberberg A, Sjöqvist BA, Ekström-Jodal B, Hjalmarson O 1991 A plethysmographic method for assessment of lung function in mechanically ventilated very low birth weight infants. Pediatr Res 30:501504

24. Edberg KE, Sandberg K. Silberberg A, Ekström-Jodal B, Hjalmarson O 1991
Lung volume, gas mixing, and mechanics of breathing in mechanically ventilated very low birth weight infants with idiopathic respiratory distress syndrome. Pediatr Res 30:496-500

25. Sandberg K, Sjöqvist BA, Hjalmarson O, Olsson T 1984 Analysis of alveolar ventilation in the newborn. Arch Dis Child 59:542-547

26. Sjöqvist BA, Sandberg K, Hjalmarson O, Olsson T 1986 Method for analysing multiple-breath nitrogen washouts. Med Biol Eng Comput 24:83-90

27. Fox WW, Schwartz JG, Shaffer TH 1979 Effects of endotracheal tube leaks on functional residual capacity determination in intubated neonates. Pediatr Res 13:60-64

\section{Announcement}

\section{Annual Meetings}

The American Pediatric Society, The Society for Pediatric Research, and The Ambulatory Pediatric Association will hold their annual meetings May 2-5, 1994 at the Washington State Convention and Trade Center, Seattle. For further information, contact APS/SPR Association Headquarters, 141 Northwest Point Blvd., P.O. Box 675, Elk Grove Village, IL 60009-0675, phone (708) 427-0205, fax (708) 427-1305 or Ambulatory Pediatric Association, 6728 Old McLean Village, McLean, VA 22101, phone (703) 556-9222, fax (703) 556-8729. 